\title{
Viscoelastic relaxation of topographic highs on Venus to produce coronae
}

\author{
Daniel M. Janes and Steven W. Squyres \\ Center for Radiophysics and Space Research, Cornell University, Ithaca, New York
}

Abstract. Coronae on Venus are believed to result from the gravitationally driven relaxation of topography that was originally raised by mantle diapirs. We examine this relaxation using a viscoelastic finite element code, and show that an initially plateau shaped load will evolve to the characteristic corona topography of central rajsed bowl, annular rim, and surrounding moat. Stresses induced by the relaxation are consistent with the development of concentric extensional fracturing common on the outer margins of corona moats. However, relaxation is not expected to produce the concentric faulting often observed on the annular rim. The relaxation timescale is shorter than the diapir cooling timescale, so loss of thermal support controls the rate at which topography is reduced. The final corona shape is supported by buoyancy and flexural stresses and will persist through geologic time. Development of lower, flatter central bowls and narrower and more pronounced annular rims and moats enhanced by thicker crusts, higher thermal gradients, and crustal thinning over the diapir.

\section{Introduction}

Ever since coronae were recognized as a unique landform on Venus from images returned by the Venera 15 and 16 spacecraft [Barsukov et al., 1984, 1986; Niko. layeva et al., 1986], their generally elevated topography. central bowl, tectonized raised annular rim, and surrounding moat have led many investigators to attribute their formation to endogenic processes, principally gravitational modification of topography raised by mantle flow [Barsukov et al., 1984; Pronin and Stofan. 1990; Stofan and Head, 1990]. This view was reinforced by the more extensive and detailed images and topographic data returned by the Magellan mission [Solomon et al., 1991; Squyres et al., 1992a]. In this model, corona formation begins with mantle diapirism raising the surface to form a broad dome that may be radially fractured. Such domes were posited as a precursor to coronae [Stofan and Head 1990], and several examples of radially fractured domes were revealed by Magellan [Squyres et al., 1992a; Stofan et al., 1992]. As the diapir flattens against the lithosphere, the model suggests that the dome assumes a more level, plateau shape [Janes et al., 1992] which then gravitationally relaxes with diapir cooling to form the final coronal topography [Stofan et al., 1991; Janes et al., 1992].

Geophysical modeling has confirmed the ability of the proposed processes of diapiric uplift and subse-

Copyright 1995 by the American Geophysical Union.

Paper number 95JE01748.

0148-0227/95/95JE-01748\$05.00 quent relaxation to form the majority of topographic and tectonic characteristics of radially fractured domes and coronae [Stofan et al., 1991; Janes et al., 1992]. However, models to date have involved simplifying assumptions that have limited their usefulness in depicting the evolution of coronae. In particular, no model to date has addressed what the topographic end state of a corona should be. The studies of the relaxation portion of corona evolution by both Stofan et al. [1991] and Janes et al. [1992] employed the viscous model of Bindschadler and Parmentier [1990]. This model includes only viscous rheology and does not consider the elastic properties of the crust and mantle, which together with isostacy, will ultimately support the load represented by the high-standing topography of coronae. The result of this simplification is that this model predicts that topography will ultimately relax entirely, producing a flat plain. In addition, although this model uses non-Newtonian flow laws for viscous rheology, it linearizes these laws by assuming that a constant, characteristic stress operates throughout the relaxation process, thus effectively treating viscosity as Newtonian. This approximation of viscous behavior permits predicted stresses during relaxation to vary from a few tens of $\mathrm{MPa}$ to a few tens of thousands of $\mathrm{MPa}$, depending on the exact choice of parameterizing constants [Stofan et al., 1991; Janes et al., 1992], and therefore fails to place reliable limits on the ability of the relaxation to produce the tectonism attributed to this stage of corona formation.

Modeling of folding on Venus [Zuber, 1987; Zuber and Parmentier, 1990] indicates that the crust and mantle are both likely to have upper portions in which rheological properties are dominated by brittle/elastic behavior and lower portions in which rheology is dom- 
inated by viscous behavior. The transition between dominant behaviors is governed by the brittle failure criterion and the power law creep behavior of the materials involved, as well as the temperature and stress profiles with depth. Recent experimental work [Mackwell et al., 1994] suggests that under the dry conditions prevalent on Venus, a diabase crust will have a much more viscous rheology than previously thought. The effects of such a rheology have not yet been evaluated for their effect on viscous relaxation of topographic highs to produce coronae.

In this paper, we address some of the short comings of previous modeling by employing a finite element analysis that includes elastic behavior, stress dependent nonNewtonian viscosity, and layered rheology. Our purpose is to answer several basic questions regarding the gravitational relaxation phase of corona formation. These open questions include the timescale of relaxation, the final topographic state, and the stress state and predicted fracture patterns at various times. We examine the dependence of each of these on crustal thickness. near-surface thermal gradient, choice of flow law for diabase, and the initial geometry of the raised topography and that of the crust/mantle boundary.

The purpose of this paper is to develop an understanding of the nature of relaxation of topography on Venus to produce coronae and particularly to determine the final equilibrium topography and stress state. It is important therefore to keep in mind the general characteristics that any model of corona relaxation must be able to reproduce. Coronae vary greatly in size, but most have radii between 100 and $200 \mathrm{~km}$ [Stofan et al., 1992]. Mature coronae (Figure 1) are characterized by several topographic and tectonic signatures [Squyres et

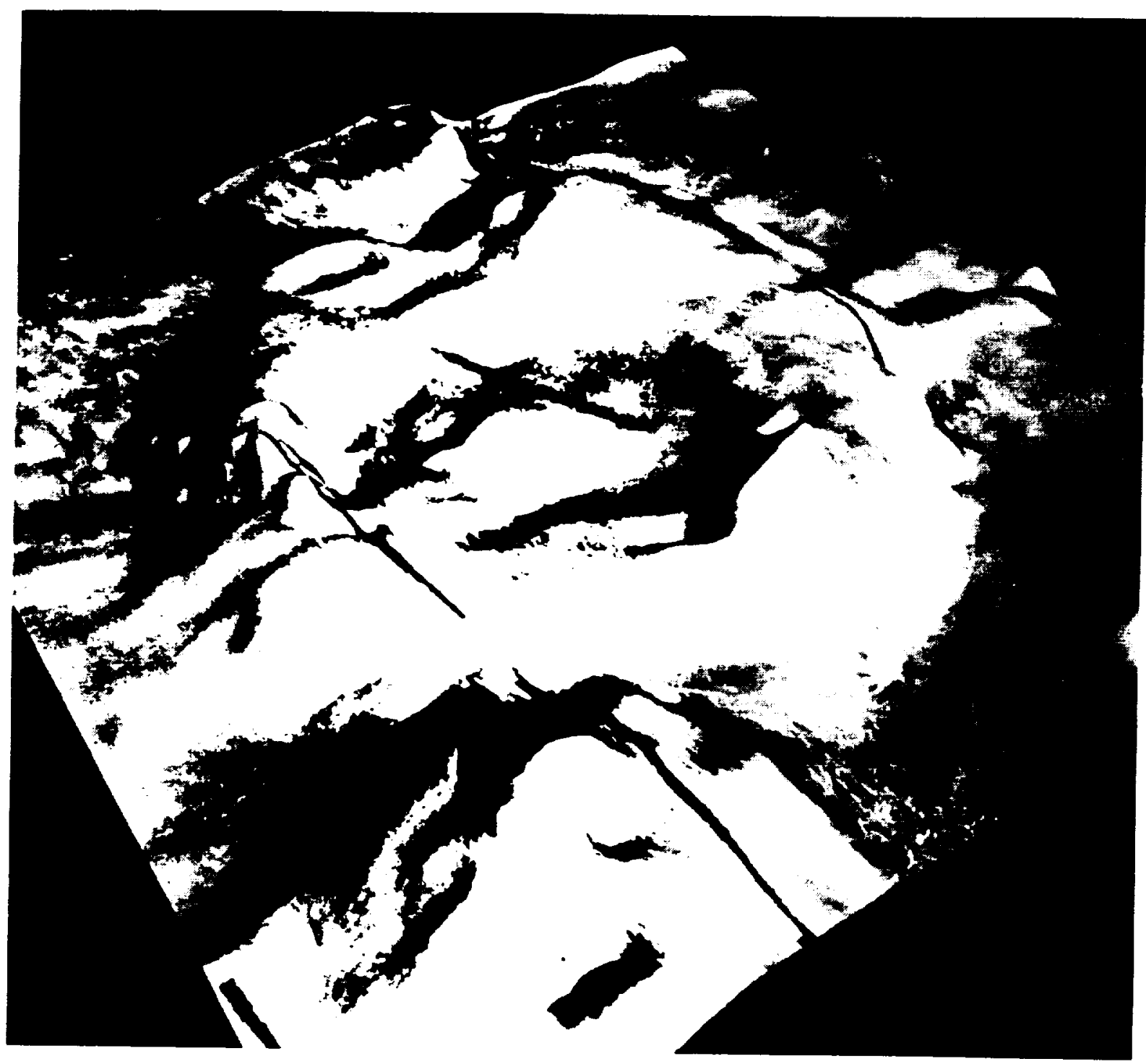

Figure 1. Perspective view of Earhart, a corona located at $70^{\circ} \mathrm{N}, 137^{\circ} \mathrm{E}$. View is from the SW. 


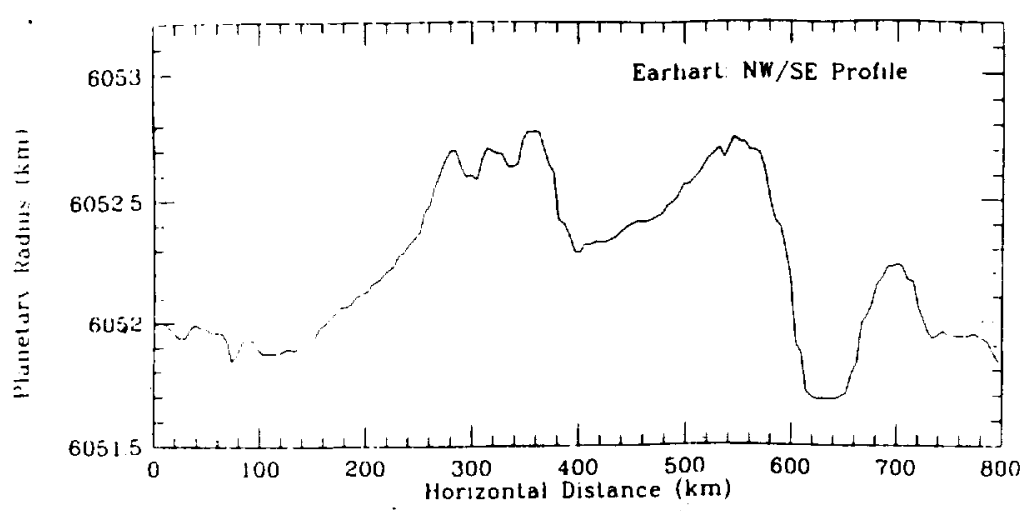

Figure 2. Topographic profile across Earhart. Profile extends from NW to SE through the center of the corona.

al., 1992a]. In topographic profile (Figure 2; also see profiles of Stofan et al. [1992] and Janes et al. [1992]) coronae commonly show a central bowl-shaped or level area that stands a few hundred meters above the level of the surrounding plains. In a few examples, the lowest portion of the central area actually lies below the plains. The next feature outward is a raised annular rim 40 to $100 \mathrm{~km}$ wide that lies $300-800 \mathrm{~m}$ above the plains and often shows evidence for concentric extensional fracturing. The rim falls off into a surrounding moat, typically 30 to $50 \mathrm{~km}$ wide and with a floor several hundred meters lower than the surrounding plains. Many outer moat walls also also show concentric fractures, generally attributed to extensional flexure and downwarping during moat formation [Stofan et al, 1991; Janes et al., 1992; Squyres et al., 1992a; Sandwell and Schubert, 1992a]. We will demonstrate that most of these features will develop during the relaxation of plateau-shaped topographic highs on Venus, and that the topographic signature of central raised depression, annular rim, and encircling moat will persist through geologic time.

\section{Model}

\section{TECTON}

To study the relaxation of topographic highs on Venus, we use the viscoelastic finite element code TECTON [Melosh and Raefsky, 1980]. We use an axisymmetric grid (Figure 3 ) in which the side nodes are fixed horizontally and are free to move vertically. The base nodes are fixed vertically and are free to move horizontally. All other nodes are free to move both horizontally and vertically. Circumferential movement is constrained by the axisymmetry to be zero. Since the base and and outer edge are fixed, they must be set far enough away from the area of interest that they do not affect its movement. Appropriate distances were found experimentally by increasing the depth and width of the grid until no change in results was observed with further increases. The grid used is $337 \mathrm{~km}$ deep and $1102 \mathrm{~km}$ wide, consisting of 13,583 nodes and 14,269 elements. Each element is assigned a set of rheological parameters including density,
Young's modulus, Poisson's ratio, and non-Newtonian flow parameters as well as an initial stress state in three dimensions. In addition, forces proportional to any vertical movement are applied at certain nodes to simulate isostatic buoyancy. We take the density of the crust to be $3000 \mathrm{~kg} / \mathrm{m}^{3}$ and that of the mantle to be 3300 $\mathrm{kg} / \mathrm{m}^{3}$. Young's modulus is taken to be $6 \times 10^{10} \mathrm{~Pa}$, and Poisson's ratio is 0.25 for both the crust and mantle [Turcotte and Schubert, 1982].

\section{Failure Envelope}

TECTON is a viscoelastic finite element code, finding displacements and stresses by considering both the viscous and elastic rheological responses of materials. However, certain rheologic responses are either viscous or elastic, and the model starting conditions must reflect these. Two such conditions are relevant to our model. One deals with the initial stress state throughout the model and the other with the application of buoyant restoring forces. To determine whether a given element is dominated by its elastic or its viscous response for these purposes, we adopt the sort of failure envelope, developed by Brace and Kohlstedt [1980], that has been used for Venus by a number of authors [e.g., Zuber, 1987; Banerdt and Golombek, 1988; Zuber and Parmentier, 1990].

Rocks can fail by either brittle failure (frictional sliding) or by plastic/viscous failure (creep). Failure will occur by the weaker of the two possible mechanisms, generally by brittle failure above and by viscous flow below some critical depth. This critical depth occurs where the differential stress required for brittle failure equals the stress required to initiate viscous flow at a geologically significant rate. The critical depth at which the changeover between predominantly elastic (brittle) behavior and predominantly viscous behavior occurs is found by comparing the differential stress required to fracture rock as predicted by Byerlee's law [Byerlee, 1978] with the differential stress required to cause the rock to flow at some geologically significant strain rate using experimentally determined flow laws.

Byerlee's law can be stated in compression as 

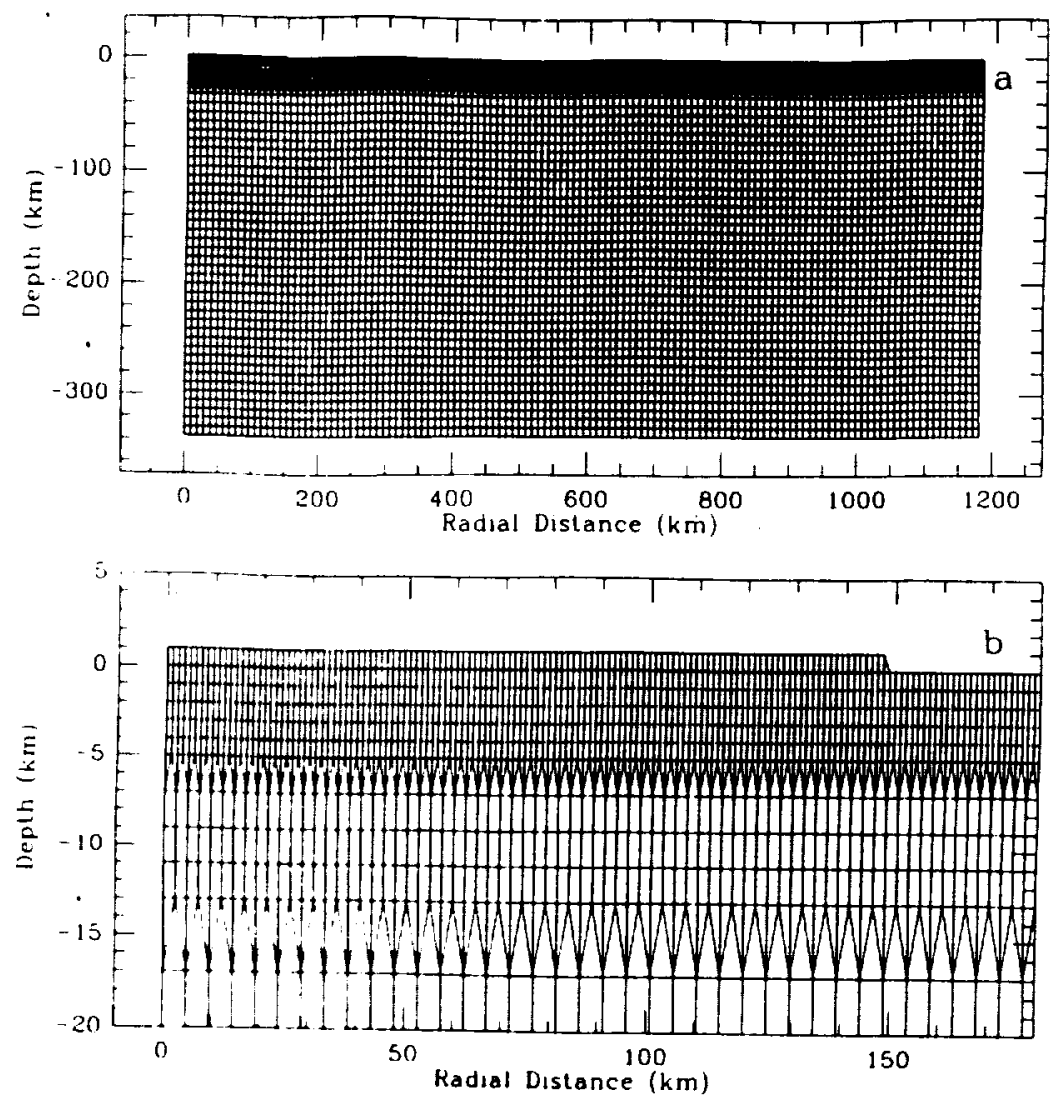

Figure 3. (a) Finite element grid employed in this study. (b) Details of upper, on-axis portion of the grid.

$$
\begin{gathered}
\Delta \sigma_{c}=3.7 \sigma_{:} \quad \sigma_{:}<1.1 \text { khar } \\
\Delta \sigma_{c}=\left(2.1 \sigma_{z}\right)+1.8 \mathrm{kbar} \quad \sigma_{:}>11 \mathrm{khar}
\end{gathered}
$$

where $\Delta \sigma_{c}$ is the stress difference $\left(\sigma_{1}-\sigma_{3}\right)$ required to produce brittle failure in compression. and in extension as

$$
\begin{gathered}
\Delta \sigma_{t}=-0.79 \sigma_{z} \quad \sigma_{:}<53 \mathrm{kbar} \\
\Delta \sigma_{t}=\left(-0.68 \sigma_{z}\right)+0.57 \mathrm{kbar} \quad \sigma_{:}>\div 3 \mathrm{hLa \textrm {hr }}
\end{gathered}
$$

where $\Delta \sigma_{t}$ is the stress difference rogure.d w produre. brittle failure in extension. We take tho v...tical stress to be that due to the overburden

$$
\sigma_{2}=\sum_{i=1}^{k}\left(\rho_{1} g h_{1}\right)
$$

where $g$ is gravity and $\rho_{1}$ and $h_{1}$ are the density and thickness of the overlying $k$ rows of elements

To model viscous behavior, non-Newtonian viscous flow laws are cast in the form

$$
\dot{\varepsilon}=A \sigma_{d}^{n} \exp (-Q / R T)
$$

where $\dot{\epsilon}$ is the strain rate, $\sigma_{d}$ is the differential stress, $R$ is the gas constant, $T$ is the absolute temperature, and $A, n$ and $Q$ are experimentally determined values. Equation (6) can be recast to determine the differential stress required for a given strain rate:

$$
\sigma_{d}=[(\dot{\epsilon} / A) \exp (Q / R T)]^{1 / n}
$$

We treat the temperature as following an error function profile from a surface temperature of $735 \mathrm{~K}$ to a constant mantle temperature of $1700 \mathrm{~K}$ [Solomon and Head, 1991]. The temperature profile is then fully described by defining the near-surface temperature gradient, or equivalently, the depth at which the mantle temperature becomes effectively constant with increasing depth. For purposes of determining the failure envelope, we take the strain rate to be $10^{-15} \mathrm{~s}^{-1}$. This is a geologically plausible strain rate, equivalent to a total strain of $3 \%$ over $1 \mathrm{~m} . y$. , and has been adopted in both terrestrial and venusian modeling [Brace and Kohlstedt, 1980; Zuber, 1987; Banerdt and Golombek, 1988; Zuber and Parmentier, 1990].

For both the crustal and mantle materials, above a critical depth at which the differential stress required to cause brittle fracturing and the differential stress required to cause viscous flow are equal, the rheological response of the rocks will be dominated by elastic behavior. Below this depth the rheology will be dominated by viscous behavior. Since we are concerned largely with the initial self-compression of the crust and mantle, as well as with the downward flexure of the litho- 


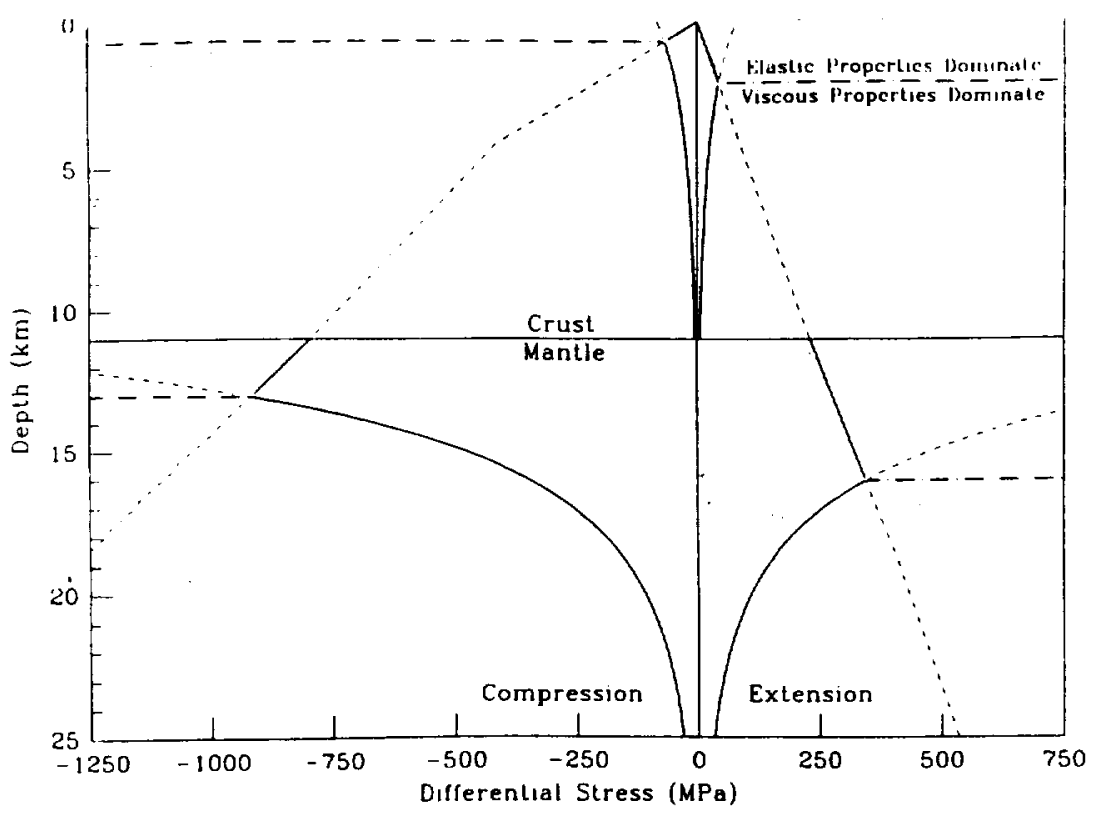

Figure 4. Failure envelopes for the crust and mantle on Venus. The model shown is for an 11 km thick diabase crust [Caristan, 1982] overlying an olivine mantle [Goetze, 1978], a near-surface temperature gradient of $15 \mathrm{~K} / \mathrm{km}$, and a strain rate of $10^{-15} \mathrm{~s}^{-1}$. Straight lines follow Byerlee's law for brittle fracture, while curved lines follow the non-Newtonian flow laws. The weaker of the two mechanisms is indicated by the heavy solid lines. Brittle-ductile transition depths are indicated by dash-dot lines with elastic strength dominating above and viscous strength dominating below these lines. Dotted lines indicate viscous strengths for strain rates of $5 \times$ $10^{-15} \mathrm{~s}^{-1}$ and $2 \times 10^{-16} \mathrm{~s}^{-1}$, showing that the depth of changeover between dominant rheological behavior is relatively insensitive to the particular choice of strain rate.

sphere under a load, we use the compressional elastic critical stress to determine the depth of changeover between dominant behaviors. A typical failure envelope calculated in the fashion described above is shown in Figure 4.

\section{Initial Conditions}

Stress state. Changes with depth in the dominant rheological response have two important implications for the starting conditions of the fintte element grid. The first of these is the initial stress state of the rocks. Rocks dominated by elastic behavior are assumed to be initially in a state of lithostatic stress

$$
\sigma_{\mathrm{r}}=\sigma_{\phi}=\sigma_{2} / 3
$$

where $\sigma_{r}$ is the radial stress and $\sigma_{\phi}$ is the hoop stress, while rocks dominated by viscous behavior are assumed to be initially in a state of hydrostatic stress:

$$
\sigma_{r}=\sigma_{\phi}=\sigma_{z}
$$

We initially take the vertical stress, $\sigma_{2}$, to be that due to the overlying layers of material with no horizontal variation, i.e., we do not include the stresses due to the initial plateau load or any changes to the crust/mantle boundary below the load. To simulate these additional stresses, we make use of the initial elastic solution of
TECTON, which returns any instantaneous displacements and resulting stresses due to the grid being initially out of equilibrium. We take the resulting stresses for each element as the starting stress state for a new elastic solution. This iterative process is repeated until all initial elastic displacements are less than $1 \mathrm{~m}$.

Buoyancy Forces. The second important implication in the change of the dominant rheological response mechanism is the imposition of buoyant restoring forces. It is sometimes erroneously thought that buoyancy requires a density contrast between materials. However, a solid material of $\rho=1.0 \mathrm{~g} / \mathrm{cm}^{3}$ immersed in water is subject to buoyancy. It is, in fact, neutrally buoyant specifically because of this force exactly counteracting the force of gravity. Buoyancy is a fluid response [Cathles, 1975], so that this restoring force must be applied at each level at which a predominantly elastic material lies on top of a predominantly viscous material, or at the boundary between two immiscible fluids. In TECTON, such a force is applied at nodes and is equal to $\rho A g \delta z$ where $A$ is the area defined by the horizontal distance between the centers of the elements on either side of the node and (since TECTON treats axisymmetric grids as extending $1 / 2$ radian from both sides of the plane of the grid for computational purposes) a concentric distance equivalent to 1 radian at the radial distance of the node, and $\delta z$ is the total vertical displacement of the node. At the changeover from elastic to viscous crust the density 
is that of the crust. At the changeover in the mantle, or at the top of the mantle if the entire mantle is dominated by viscous rheology, the density is the difference between the crustal and mantle densities, since the buoyancy of the crustal material will have already been applied at the appropriate level in the crust. For cases where the entire crust is dominated by elastic behavior, a single set of buoyancy forces is applied in the mantle, proportional to the mantle density.

\section{Time Steps and Ending Conditions}

The size of the time steps used during model runs is determined on the basis of the smallest Maxwell time for any element in the grid, defined as the ratio of that element's viscosity to its Young's modulus. Time step size is constrained to be less than $10 \%$ of the Maxwell time during most of each run, but can be gradually increased to $30 \%$ of the Maxwell time at late stages when the relaxation is nearly complete and relaxation rates are small. Model runs using shorter time steps show no changes in calculated topography or stress. The limiting Maxwell time increases as viscous relaxation progresses. We have determined that the limiting Maxwell time as a function of time can be well fit by the relationship

$$
\log \left(\tau_{M}\right)=a+\left[\begin{array}{ll}
b & \log t
\end{array}\right]
$$

where $\tau_{M}$ is the Maxwell time and $t$ is the time. In practice, we determine the initial limiting Maxwell time during the elastic iterations used to determine the starting stress state. We then use a time step size which is $10 \%$ of the initial Maxwell time and allow the grid to deform through a few thousand time steps. Actual Maxwell times are then determined at specific time steps, and the values of $a$ and $b$ in (10) are determined and used to calculate the predicted $\tau_{M}$ as a function of time for a particular run. Time step size is then increased as Maxwell time increases. Runs terminate when equilibrium is reached and velocities have dropped to zero. At this point, remaining topography is supported by a combination of isostatic and elastic forces, and no further relaxation occurs.

\section{Crust/Mantle Boundary}

The process thought to produce coronae [Stofan et al., 1991; Janes et al., 1992; Squyres et al. 1992a] begins with a rising mantle diapir which impinges on the underside of the lithosphere, raising domical topography which, as the diapir spreads beneath the lithospheric lid, becomes more plateau shaped. The rising diapir also carries heat which would serve to raise the near-surface temperature gradient and to lower the critical differential stress required for viscous flow in both the upper mantle and lower crust. If the crust is dynamically coupled to the mantle flow at its base, lower portions of the crust may then become entrained in the outward mantle fow above the diapir head, creating a cavity in the crust which would be filled with rising diapir and/or mantle material [Bindschadler and Parmentier, 1990]. Such crustal thinning would result in a higher density and rheologically separate mantle material in place of the lower portions of the thinned crust. We model such crustal thinning and infilling in some of our runs by assigning mantle rheology and density to elements under the load, extending upward from the mantle and laterally to a distance equal to the radius of the plateau.

\section{Results}

\section{"Standard" Case}

Many studies have determined plausible ranges for Venus' crustal thickness and thermal gradient. Determinations of crustal thickness from modeling of formation of regularly spaced tectonic lineations [Zuber, 1987; Banerdt and Golombek, 1988; Zuber and Parmentier. 1990] yield values of 5 to $30 \mathrm{~km}$. Crater relaxation models [Grimm and Solomon, 1988] give 10 to $20 \mathrm{~km}$, and inversion of gravity and topography [Herrick and Phillips, 1992] implies a global average of $15 \mathrm{~km}$. The crust could be significantly thinned over sites of mantle upwelling, particularly if the mantle flow breaches the upper elastic mantle [Bindschadler and Parmentier, 1990]. To cover a meaningful range of values, we examine crustal thicknesses of 5,11 , and $21 \mathrm{~km}$.

Thermal gradients have also been determined by many of the same studies [Zuber, 1987; Banerdt and Golombek, 1988; Zuber and Parmentier, 1990; Grimm and Solomon 1988] to range between 10 and $25 \mathrm{~K} / \mathrm{km}$. Simple conduction models [Solomon and Head, 1982] and flexural studies [Solomon and Head, 1990] yield similar values. At the extremes, Sandwell and Schubert [1992b], modeling lithospheric flexure at large coronae, found thermal gradients as low as $7 \mathrm{~K} / \mathrm{km}$, while Squyres et al. [1992b], modeling buckling wavelengths in the plains, found values as high as $30 \mathrm{~K} / \mathrm{km}$. We examine nearsurface temperature gradients of 5,15 , and $30 \mathrm{~K} / \mathrm{km}$.

As a "standard" case for comparison with later results, we. first examine the case of a $1 \mathrm{~km}$ high plateau load, $150 \mathrm{~km}$ in radius, on an $11 \mathrm{~km}$ thick crust with a near-surface temperature gradient of $15 \mathrm{~K} / \mathrm{km}$. We model the viscous behavior of the crust using the diabase flow law of Caristan [1982] and of the mantle using the olivine flow law of Goetze [1978]. For this case, the changeover from predominantly elastic to predominantly viscous behavior occurs in the crust at a depth of $680 \mathrm{~m}$ and in the mantle at a depth of $13 \mathrm{~km}$ (Figure 4). Relaxation predicted by the model (Figure $5 \mathrm{a}$ ) proceeds very rapidly, with most of the motion occurring within the first year. The plateau relaxes to very near its final shape in approximately 100,000 years, with only limited movement between 100,000 and 400,000 years. By about 400,000 years, equilibrium has been reached, the remaining load is supported by buoyancy and flexural stresses, and no further significant relaxation occurs.

In reality, relaxation of topography raised by a hot diapir will be slower than our model predicts. This is because the model essentially assumes that the diapir that raised the topography cooled instantaneously, re- 

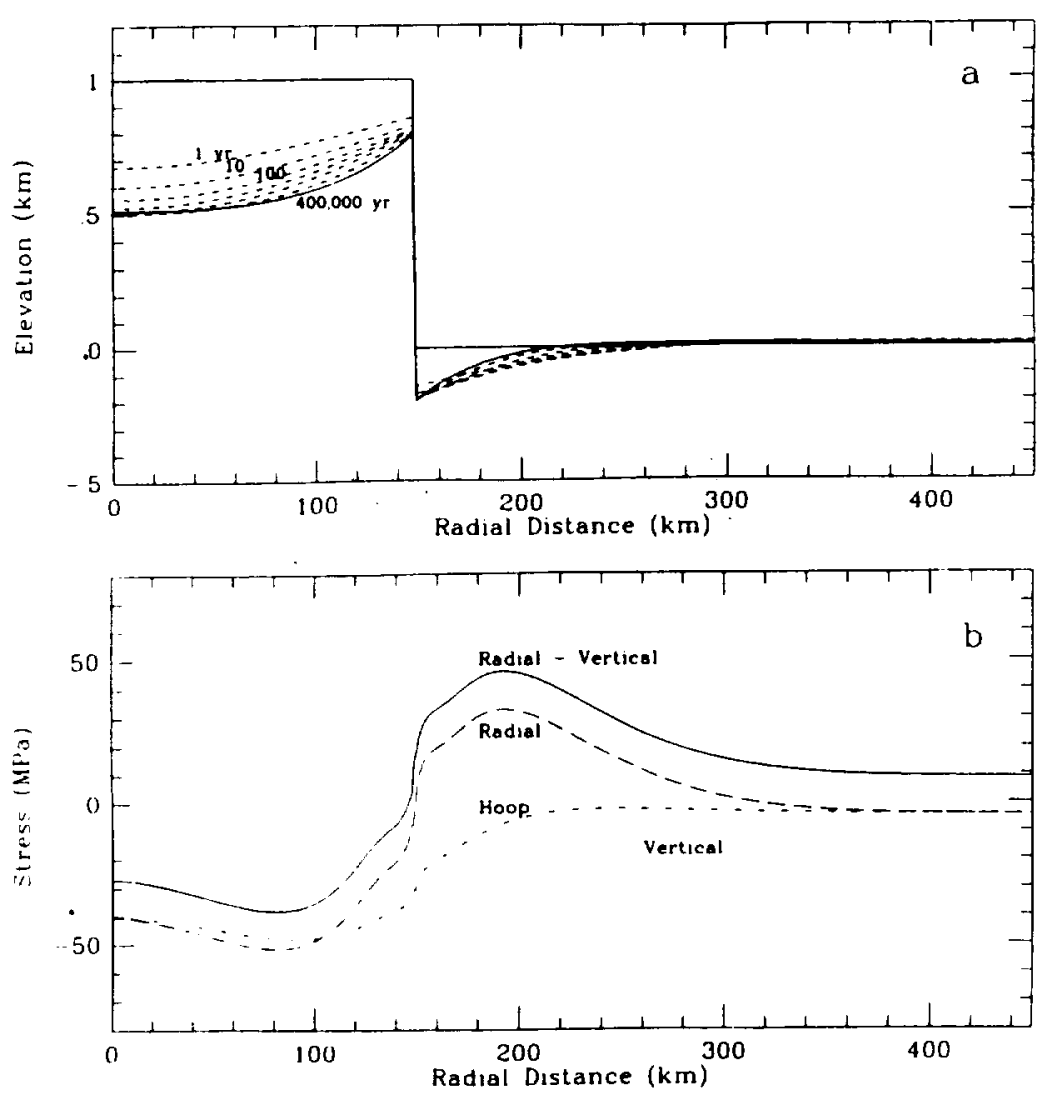

Figure 5. (a) Topographic profiles through time for a $1-\mathrm{km}$ plateau load on an $11-\mathrm{km}$ crust with a near-surface temperature gradient of $15 \mathrm{~K} / \mathrm{km}$. Profiles are shown at 1 year, 10 years, 100 years, etc. (b) Near surface stresses for the case shown in Figure 5a at 10,000 years.

sulting in a state that is well out of equilibrium. This disequilibrium results in large stresses and low viscosities. In reality, relaxation rates would be controlled by the cooling rate of the underlying diapir rather than by the rheology of the mantle and crust. We can contrast model-derived relaxation times with a characteristic cooling time for a diapir emplaced beneath the crust or lithosphere of Venus. Cooling of a diapir can be treated simply as a one-dimensional, time-dependent heat conduction case with a characteristic cooling time $\tau_{c}$ [Turcolte and Schubert, 1982] of:

$$
\tau_{c}=l^{2} / \kappa
$$

where $l$ is a characteristic length scale and $\alpha$ is the thermal diffusivity. As an illustrative case, consider pable of responding essentially instantaneously to the cooling of the diapir. Any significant lag behind the withdrawal of thermal buoyancy will act to increase the differential stresses and thus decrease viscosity. This, in concert with viscosity decreases due to the higher temperatures in the vicinity of the cooling diapir, will keep relaxation rates high enough to follow cooling. We will therefore concentrate on the final topographic state of the relaxed corona, which is dependent on the rheology only, rather than the relaxation timescale, which is not.

As expected, our model reproduces all the major topographic signatures of coronae. These form very early in the relaxation process and become more pronounced with time. The central bowl, high-standing rim, and exterior moat are all apparent early in the relaxation. Later, the central bowl sinks to lower elevations and becomes broader and flatter. The raised rim becomes narrower and more pronounced as its maximum elevation decreases less rapidly than that of the central bowl. At its final equilibrium state, the crest of the rim sits approximately $300 \mathrm{~m}$ above the central bowl and $800 \mathrm{~m}$ above the surrounding plains level. Similarly, the moat becomes slightly narrower and deeper, reaching a final depth some $200 \mathrm{~m}$ below the plains.

Stresses at a depth of $0.5 \mathrm{~km}$ (the midpoint depth of surface elements in the model) reach their maximum differential magnitude after approximately 10,000 years (Figure 5b), when the topography has relaxed to nearly 
its final state. The stresses remain essentially the same with further relaxation. Stresses in the three principal stress axes are compressional within the load, while the radial and hoop stresses become extensional beyond the load. The vertical stress is constant, representing $\rho g h$ at a depth of $0.5 \mathrm{~km}$ within the upper layer of the load and the crust beyond the plateau load. Maximum differential stresses in the interior bowl region of the corona are compressional and relatively small, reaching a maximum of about $40 \mathrm{MPa}$ (vertical minus radial) at a radial distance of $80 \mathrm{~km}$. The vertical stress is the least compressional, and the radial stress is the most compressional, which could result in concentric thrust faulting if the stress levels were high enough [Anderson, 1951]. However, rocks are strong enough in compression that the relatively low differential stress at this point would be unlikely to produce such faulting. Indeed, concentric thrust faults are not generally found within the central basins of coronae.

Beyond the edge of the plateau, the near-surface radial stress is the most extensional, while the vertical stress is the most compressional, leading to the expectation of concentric normal faulting. The maximum differential stress reached is $46 \mathrm{MPa}$ at a radial distance of $190 \mathrm{~km}$. The differential stress is above $40 \mathrm{MPa}$ over a range of 170 to $220 \mathrm{~km}$ from the corona center. This coincides with the outer wall of the moat surrounding the raised rim, in the region where concentric grabens are observed on the moats of many coronae [Squyres et al., 1992a]. The predicted stress level is close to the $50 \mathrm{MPa}$ estimated to be required for fault propagation in Venusian surface rocks [Janes et al, 1992]. There is a narrow area on the lowermost portions of the exterior wall of the moat where the radial stress is the most extensional and the hoop stress is the most compressional. Simple Anderson [1951] failure criteria would predict strike-slip faulting here if stress levels were high enough, though it is not clear that Anderson criteria can accurately predict strike-slip faulting in such an environment [Schultz and $Z u b e r, 1994]$. No such faulting is generally observed here in coronae, and predicted differential stresses in this region are relatively small, approximately $30 \mathrm{MPa}$, so that in any case the absence of faulting is not unexpected. The location of the maximum differential stress on the outer wall of the moat moves closer to the corona center with increasing relaxation. The maximum occurs initially at a radial distance of $230 \mathrm{~km}$, moving inward as relaxation progresses.

One striking discrepancy between model predictions and observed tectonics is the absence of a model prediction of concentric fracturing on the raised rim of the corona. Stresses on the rim are compressional, with the hoop stress the most compressional and the radial stress the least compressional so that, if anything, strike-slip faulting would be expected according to Anderson criteria. However, the differential stress in this region is only $20 \mathrm{MPa}$ or less. The lack of a prediction of the formation of concentric fractures on the rim during relaxation suggests that the fractures observed on corona rims form at some other stage of corona evolution. For example,
Koch [1994] suggests that this set of fractures forms during the transition from radially fractured domes to uplifted plateau, as bending of the surface is concentrated at the edge of the plateau that will later form the raised rim.

\section{Crustal Thickness}

Proceeding from the "standard" case described above, we first examine the effects of crustal thickness on relaxation. Figure 6 a shows final profiles for crustal thicknesses of 5,11 , and $21 \mathrm{~km}$ with a $15 \mathrm{~K} / \mathrm{km}$ near-surface temperature gradient. It also shows a topographic profile across the corona Earhart. Relaxation takes longer for the $5-\mathrm{km}$ crust than for an $11-\mathrm{km}$ crust, reaching equilibrium after 800,000 years. This time span, however, is still considerably shorter than the expected cooling time for the diapir which raised the initial plateau, so that relaxation time will still be controlled by cooling. The final topography is very similar to that produced by the thicker crust.

For the 21-km-thick crust, all of the mantle is below the depth at which the dominant rheological behavior changes from elastic to viscous. The entire mantle is therefore initially in hydrostatic equilibrium, and manthe buoyancy forces are applied at the top of the mantle. The equilibrium topography is reached after only 140,000 years of model relaxation. The topographic signatures are more pronounced, with a broader flattened region in the interior and narrower raised rim and surrounding moat. Late in the relaxation of this case, the center of the bowl rebounds slightly as load stresses transmitted by outer portions of the raised bowl dissipate with the continued relaxation of that portion of the corona. This rebound results in the center of the corona having a gentle dome rising a few tens of meters above the lowest level of the interior bowl.

The model derived topography for all three crustal thicknesses generally fits that of the corona Earhart, in that they match the height of the central bowl and raised rim as well as the depth of the moat. However, the actual rim and moat are more separated and the slope between them shallower than that predicted by the model. This is almost certainly due to the fact that the model starts with an arbitrarily steep, step function plateau, whereas in reality, the slope of the plateau will likely be less pronounced. We will show, however, that relaxation of initial loads as broadly sloped as might be formed by thick extrusive flows will produce neither a central bowl nor raised rim.

In Figure 6b, we plot the maximum radial-vertical differential stress, which would be responsible for concentric tectonics, for each of the three different crustal thicknesses. The stress state reached with a 5-km-thick crust is very similar to that for the $11-\mathrm{km}$ case, having a maximum of approximately $45 \mathrm{MPa}$ on the outboard wall of the moat. Relaxation of a 21-km-thick crust leads to a more sharply localized rim and moat (Figure $6 a$ ), and the maximum differential stress state is also more sharply defined. The differential stress reaches approximately $55 \mathrm{MPa}$ at a distance of $160 \mathrm{~km}$, closer 

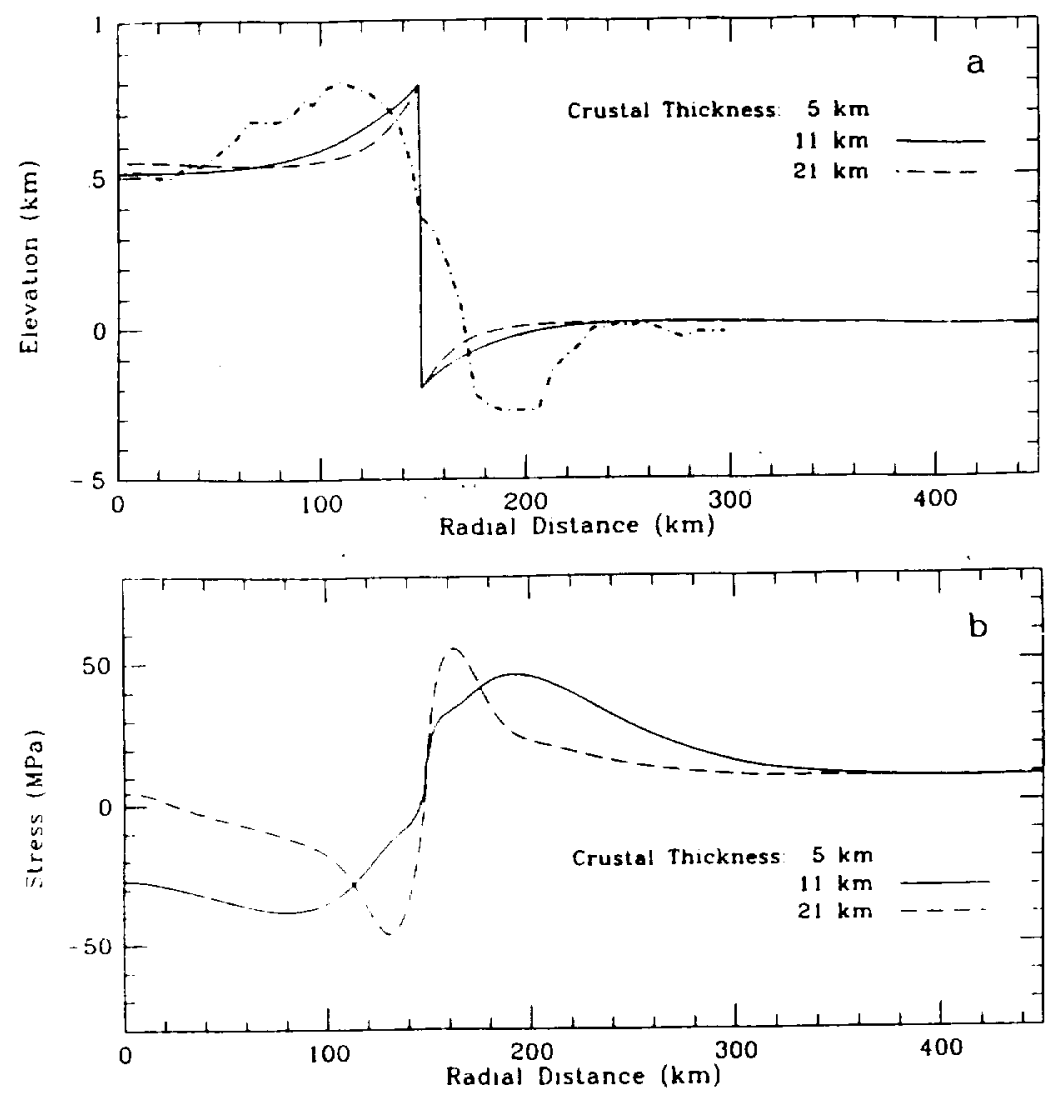

Figure 6. (a) Final equilibrium topographic profiles for a $1-\mathrm{km}$ plateau load on 5- (dotted), 11- (solid), and 21- (dashed) $\mathrm{km}$ crusts with a near surface temperature gradient of $15 \mathrm{~K} / \mathrm{km}$. The heavy dash-dot line is a topographic profile across the corona Earhart. (b) Maximum near surface stresses developed for the cases shown in Figure 6a.

to the center than both the $5-\mathrm{km}$ and $11-\mathrm{km}$ crust cases Differential stress exceeds $50 \mathrm{MPa}$ over an annulus between 160 and $170 \mathrm{~km}$ and exceeds $40 \mathrm{MPa}$ between 150 and $180 \mathrm{~km}$. Therefore the width of the area of possible concentric fracturing narrows with increasing crustal thickness. Compressional stresses on the rim are also larger for thinner crusts, but still only reach a maximum of $50 \mathrm{MPa}$.

\section{Temperature Gradient}

To examine the effects of the near-surface thermal gradient on plateau relaxation, we ran additional models with different thermal gradients. Figure 7 a shows the results for an $11-\mathrm{km}$-thick crust with temperature gradients of 5,15 , and $30 \mathrm{~K} / \mathrm{km}$, as well as a topographic profile across the corona Mama Alipa. With the shallower gradient, the changeover to viscous behavior occurs deeper in both the crust and mantle. In the crust, the changeover depth is $760 \mathrm{~m}$, while in the mantle it is $32 \mathrm{~km}$. For the steep $30 \mathrm{~K} / \mathrm{km}$ gradient the crustal changeover depth is $590 \mathrm{~m}$, and the entire mantle is dominated by viscous behavior.

Due to the temperature dependence of viscosity, relaxation takes somewhat longer with the shallower temperature gradient, reaching equilibrium in $1 \mathrm{~m} . \mathrm{y}$., still shorter than most expected cooling times. The final topography is less pronounced than that found for the steeper $15 \mathrm{~K} / \mathrm{km}$ gradient. The central elevation of the bowl is higher, and the rim and moat have shallower, broader slopes. The rim stands only $150 \mathrm{~m}$ above the central bowl, and the moat reaches a depth of only 180 $\mathrm{m}$ below the surrounding plains. These differences are most likely due to the thicker portions of the crust and mantle that are dominated by elastic strength, and that therefore are able to flexurally support the load without failing by viscous flow.

With a thermal gradient of $30 \mathrm{~K} / \mathrm{km}$, relaxation proceeds very rapidly in the model and reaches equilibrium in only 10,000 years. Otherwise, the effects on final topography are generally similar to those produced by a thicker crust, with a narrowly defined rim and moat and a gentle rise in the central depression as relaxation reaches completion.

As was the case with Earhart (Figure 6a), model derived rim height and moat depth provide a reasonable fit to that observed at Mama Alipa (Figure 7a), although a regional slope prevents a better fit to the flexure outboard of the moat. The topography of Mama Alipa shows a relatively sharp slope between the rim and moat, indicating that it might have been more sharply plateau shaped initially than was the case for Earhart. The depth of the central bowl implies a thermal gradi- 

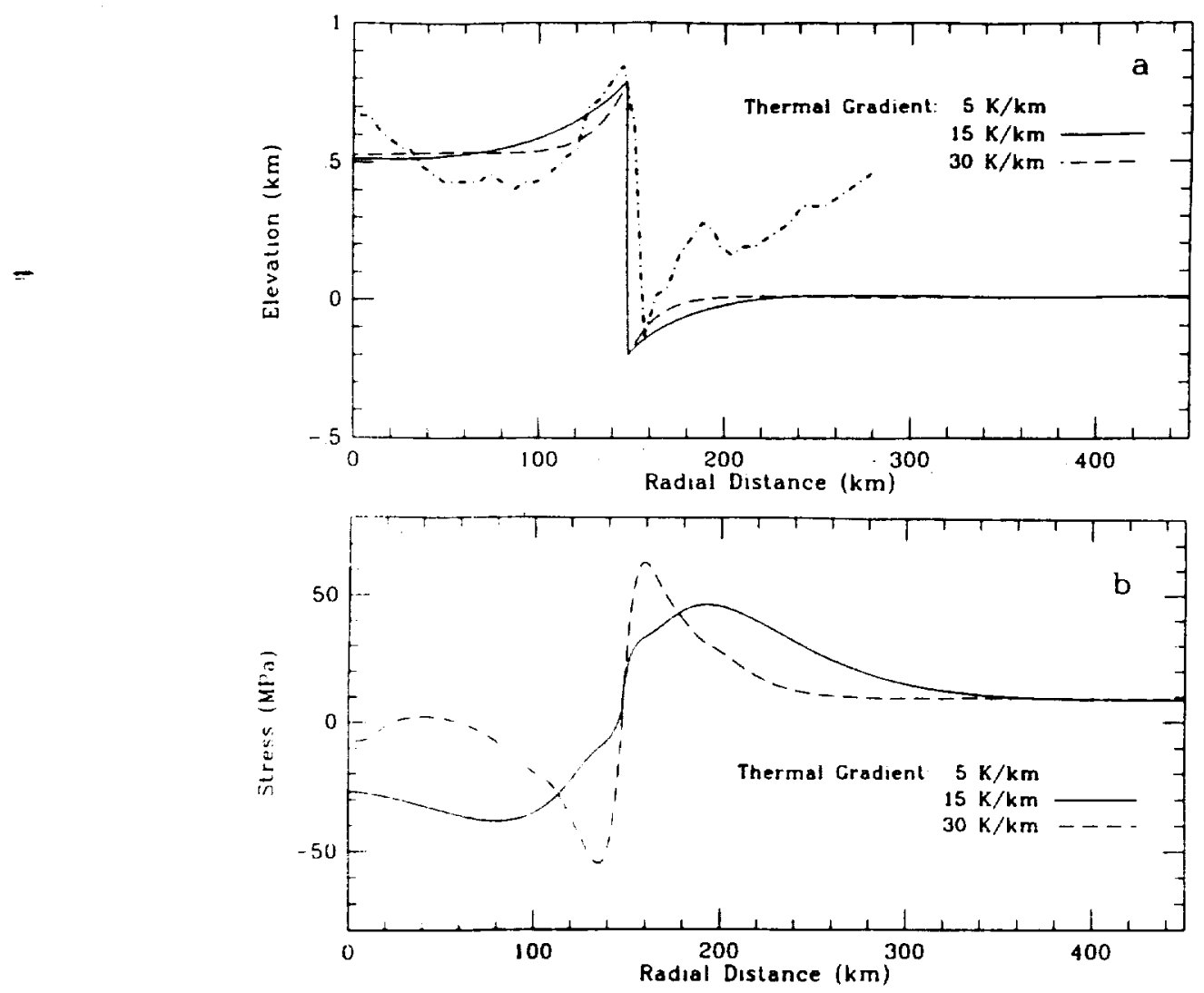

Figure 7. (a) Final equilibrium topographic profiles for a $1-\mathrm{km}$ plateau load on an $11-\mathrm{km}$ crust with a near surface temperature gradients of 5- (dotted), 15- (solid), and 30 - (dashed) $\mathrm{K} / \mathrm{km}$. The heavy dash-dot line is a topographic profile across the corona Mama Alipa. (b) Maximum near surface stresses developed for the cases shown in Figure $7 \mathrm{a}$.

ent of at least $15 \mathrm{~K} / \mathrm{km}$, since shallower gradients would result in a shallower depression.

The effect of thermal gradient on the maximum differential stress developed during relaxation (Figure ib) is similar to that produced by crustal thickness variations (Figure 6b), but is more pronounced. For a $5 \mathrm{~K} / \mathrm{km}$ gradient, the maximum differentıal stress is low and broadly distributed compared to the higher 15 $\mathrm{K} / \mathrm{km}$ case. In the region of concentric extension it reaches only about $25 \mathrm{MPa}$ at a distance of $240 \mathrm{~km}$. The central compressional stress is approximately 40 MPa. Conversely, a steep $30 \mathrm{~h} / \mathrm{km}$ gradient produces stresses that are both greater in magnilude and more narrowly confined to the moat and $\mathrm{nm}$ region. Stresses reach a maximum differential stress of about $60 \mathrm{MPa}$ in the area of concentric normal faulting on the outer wall of the moat at a distance of $160 \mathrm{~km}$.

In summary, both higher thermal gradients and thicker crusts produce more sharply defined corona topography and higher stresses. The center of the initial plateau typically subsides to approximately one half its original height of $1 \mathrm{~km}$. The exception is when a very low thermal gradient results in such thick elastically dominated portions of the crust and mantle that the center remains high. In the most advantageous case of a thick crust and $a$ high thermal gradient, the differential stresses on the outer wall of the moat are greater than the $45 \mathrm{MPa}$ maximum brittle extensional strength of the crust (Figure 4) and the $50 \mathrm{MPa}$ fault propagation strength of the Venusian crust inferred by Janes et al. [1992].

\section{Viscous Flow Law}

Recent laboratory experiments have indicated that under the very dry conditions on Venus, diabase may exhibit a more viscous behavior than previously thought [Mackwell et al., 1994]. We have run models using this new flow law to determine the effect it would have on relaxation of plateaus on Venus. Figure $8 \mathrm{a}$ shows results for 5-, 11-, and 21-km thick crusts with a viscous rheology that follows the flow law of Mackwell et al. [1994] and a near surface temperature gradient of 15 $\mathrm{K} / \mathrm{km}$. For this rheology and temperature gradient, the entire $5 \mathrm{~km}$ thick crust is dominated by elastic behavior, while the 11 - and $21-\mathrm{km}$ thick crusts change from dominantly elastic to dominantly viscous at a depth of $7 \mathrm{~km}$. In all cases, the mantle changeover occurs at a depth of $13 \mathrm{~km}$. Topographic profiles after relaxation are essentially unchanged from those obtained using the flow law of Caristan for the 5- and 11-km-thick crusts, implying that, at least when the crust is relatively thin, relaxation is controlled primarily by the mantle viscosity rather than that of the crust. However, there is a significant change in the final relaxed profile for thicker crusts. The $21 \mathrm{~km}$ thick crust using the Mackwell flow 

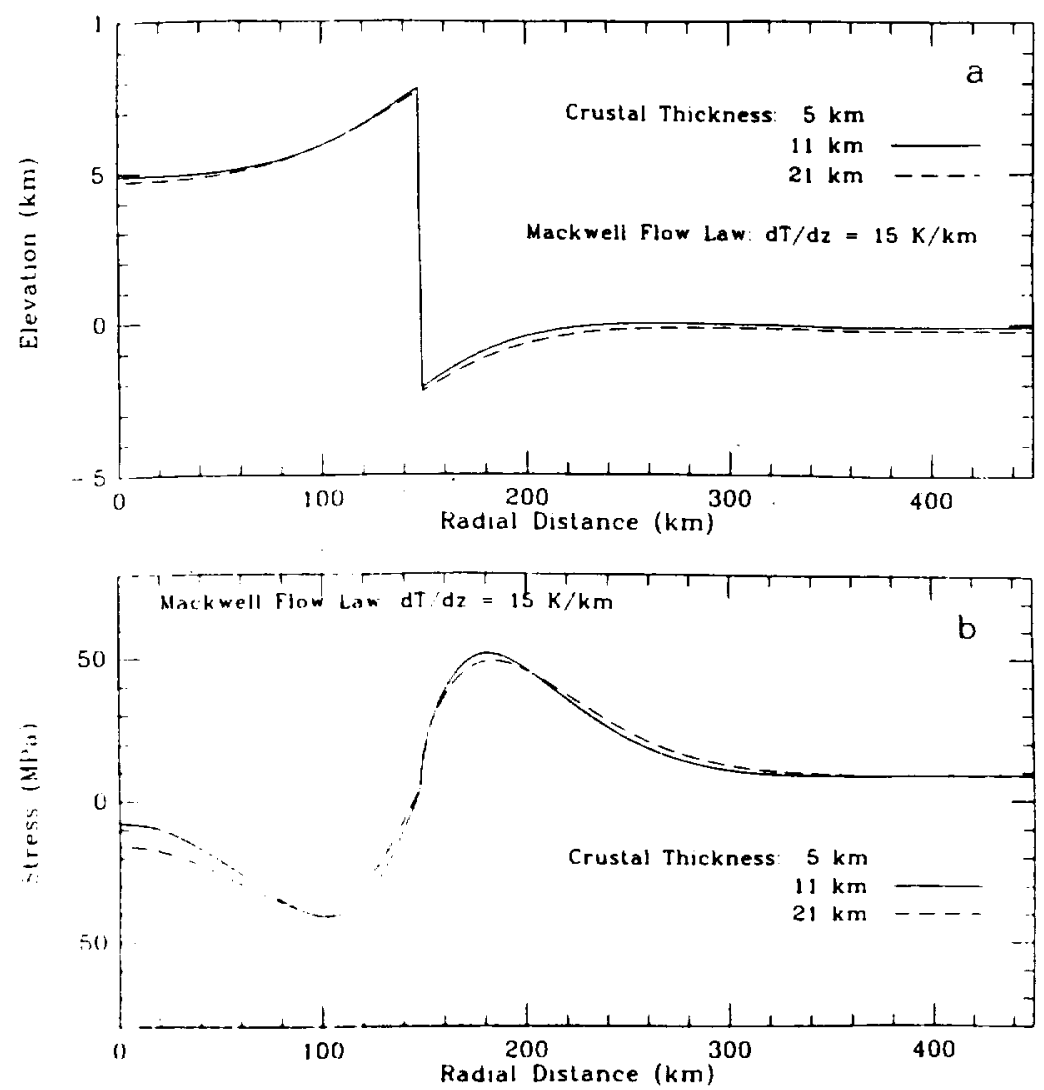

Figure 8. (a) Final equilibrium topographic profiles for a 1-km plateau load on 5- (dotted), 11(solid), and 21- (dashed) $\mathrm{km}$ crusts with a near surface temperature gradient of $15 \mathrm{~K} / \mathrm{km}$ and employing the viscous flow law of Mackuell et al. [1994]. (b) Maximum near surface stresses developed for the cases shown in Figure sa.

law does not develop the low central upluft wen with the softer material. In addition. the rmin and moan are less sharply peaked, resulting in a final profile. which is virtually indistinguishable from the thinner crust cases

The more viscous crustal rheology smmlari! alfects surface stresses (Figure 8b). Stresses for the $;$ - and $11-\mathrm{km}$-thick crusts are similar to those obtanned using the Caristan flow law (Figure 6a) Howeser. stresses developed in a $21-\mathrm{km}$-thick crust are mathedl! changed when using the more viscous Mackurll flon lan As was the case with topography, stresses remann mentally unchanged as the crust thickens and do not drevelop sharply peaked differential stresses in the areis of the rim and moat.

The main effect of using the more viscous dhatiase flow law is to increase the time required for the models to reach equilibrium. However, even these extended umes are shorter than the expected diapir cooling times. Maximum differential stresses become slightly larger, develop over a wider area, and occur significantly later in the relaxation process. For crusts that are as thick as $21 \mathrm{~km}$, the increased crustal viscosity also produces a broadening of the moat and rim.

\section{Crust/Mantle Boundary}

The models we have examined so far have assumed that the crust/mantle boundary occurs at the same depth under the raised topography as under areas beyond. However, the generalized model of corona formation posits that the raised topography is due to uplift of the elastic lithosphere by a rising mantle diapir. Mantle flow above the diapir will be outwards along the base of the crust, raising the possibility that the lower crust will become entrained in this flow, resulting in crustal thinning [Bindschadler and Parmentier, 1990]. In order to examine the effects of replacing these portions of the crust with mantle material, we have run models in which elements that lie at depths between the nominal crust/mantle boundary and a depth of approximately one half the crustal thickness, and which are under the initial plateau topography, are assigned mantle material properties.

The replacement of crust with mantle material results in several changes in final topography, and maximum differential stress. For a $5 \mathrm{~km}$ crust (using the Caristan flow law) with mantle material replacing the lower $2 \mathrm{~km}$ of the crust, the excess mass causes the central bowl to descend an additional $200 \mathrm{~m}$ to a height $400 \mathrm{~m}$ above the plains level (Figure 9a). The rim and moat topography becomes narrower and more pronounced, the rim standing $350 \mathrm{~m}$ above the bowl and $750 \mathrm{~m}$ above the plains, while the moat reaches a depth of nearly 250 $\mathrm{m}$. For an $11-\mathrm{km}$-thick crust with mantle material filling the lower $5 \mathrm{~km}$ below the plateau, the bowl of the 

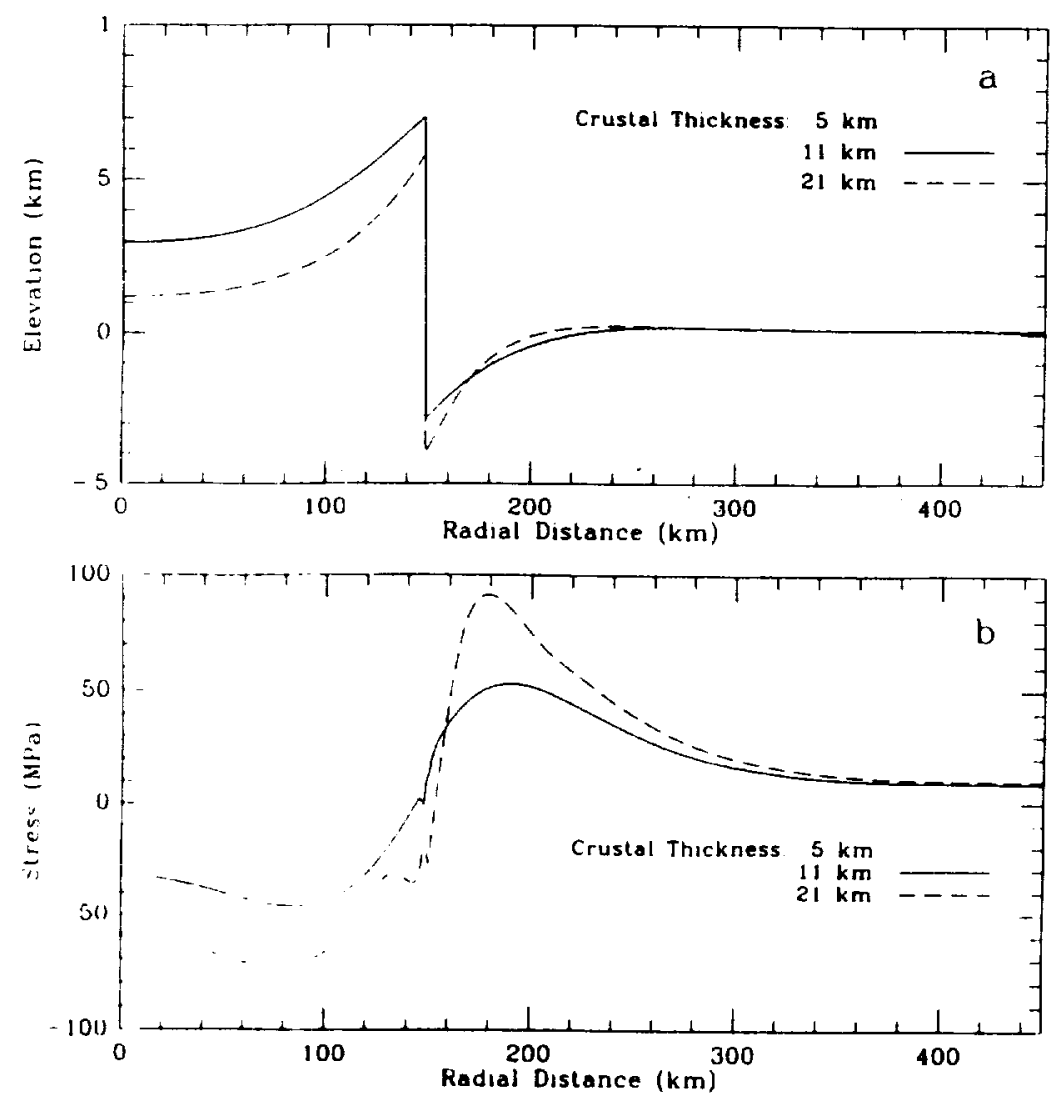

Figure 9. (a) Final equilibrium topographic profiles for a $1-\mathrm{km}$ plateau load on a $5-\mathrm{km}$ crust with mantle material intruding into the lower $2 \mathrm{~km}$ of the crust under the load (dotted), an $11-\mathrm{km}$ crust with mantle material intruding into the lower $5 \mathrm{~km}$ (solid), and a 21-km crust with mantle material intruding into the lower $10 \mathrm{~km}$ (dashed). All cases have a near surface temperature gradient of $15 \mathrm{k} / \mathrm{km}$. (b) Maximum near-surface stresses for the cases shown in Figure 9a.

corona would now lie some $300 \mathrm{~m}$ above tlin. surrounding plains. The rim lies $400 \mathrm{~m}$ above the center and 700 $\mathrm{m}$ above the plains, while the moat is approximately $300 \mathrm{~m}$ deep. The rim and moat topography is also similar to the $5 \mathrm{~km}$ case, being narrower and steeper than was the case without crustal thinning (Figure ia). In the case of a $21-\mathrm{km}$-thick crust with mantle material infiltrating the lower $10 \mathrm{~km}$. the central bowl descends to nearly the level of the surrounding planns. lyung only $100 \mathrm{~m}$ above them (Figure $9 \mathrm{a}$ ). This greater depression of the central bowl makes the rim more pronounced. It now stands some $500 \mathrm{~m}$ above the center even though it lies only $600 \mathrm{~m}$ above the level of the plains. The moat becomes both deeper and wider, reaching a depth of $400 \mathrm{~m}$ and a width of about $50 \mathrm{~km}$. The rebound of the center to form a gentle dome which was evident in the 21-km-thick crust (Figure 6a) still occurs but is much less pronounced.

Stresses, as well as topography, become higher and more sharply focused with replacement of the lower crust by mantle material. The peak differential stress on the outer wall of the moat for the $5 \mathrm{~km}$ thick crust is 53 MPa (Figure 9b). Differential stresses are greater than $50 \mathrm{MPa}$ over radial distances of 175 to $200 \mathrm{~km}$ from the corona center. Without mantle material displac- ing portions of the crust, stresses in this region never exceed $50 \mathrm{MPa}$. Thus the replacement of crustal material with higher density mantle makes development of a broad annulus of concentric extensional fracturing more likely than would otherwise be the case. Compressional stresses within the bowl are also higher but reach a maximum differential stress of only $47 \mathrm{MPa}$, probably inadequate to produce compressional tectonism. Differential stresses in the $11 \mathrm{~km}$ thick crust reach a maximum of $64 \mathrm{MPa}$ at a radial distance of $190 \mathrm{~km}$. Stresses are greater than $50 \mathrm{MPa}$ from 160 to $220 \mathrm{~km}$, while compressional stresses in the bowl reach a maximum of $60 \mathrm{MPa}$ at a distance of $85 \mathrm{~km}$. For the $21 \mathrm{~km}$ thick crust having the lower $10 \mathrm{~km}$ replaced with mantle material, stresses on the outer wall of the moat reach a maximum of $92 \mathrm{MPa}$ and exceed $50 \mathrm{MPa}$ from 160 to $225 \mathrm{~km}$. In this case, however, compressional stresses within the bowl are also much larger, reaching $71 \mathrm{MPa}$ at a radial distance of $79 \mathrm{~km}$, large enough that one might begin to expect to see concentric thrust faulting and/or folding under these conditions.

Topography and tectonics similar to those our modeling predicts to result from significant crustal thinning are seen at a few coronae on Venus. For example, Squyres et al. [1992a], describe the rim of the 


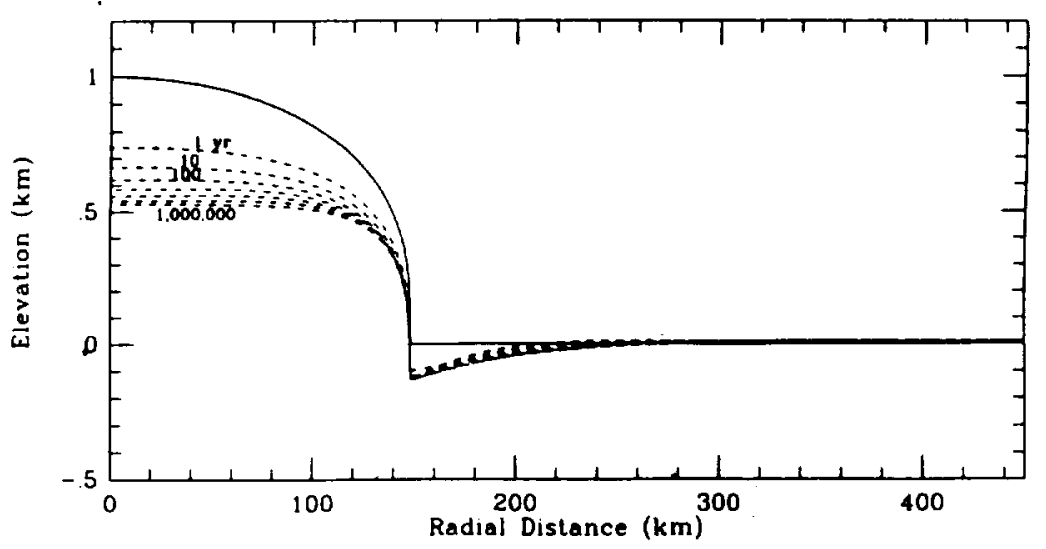

Figure 10. Final equilibrium topographic profiles for a $1-\mathrm{km}$ parabolic load on an $11-\mathrm{km}$ crust with a near surface temperature gradient of $15 \mathrm{~K} / \mathrm{km}$.

corona $\mathrm{Ba}$ 'het as lying less than $400 \mathrm{~m}$ above the surrounding plains while its interior is at or slightly below plains level. They also note that, while the majority of the concentric tectonics around $\mathrm{Ba}$ 'het are extensional in nature, the innermost ring of features at its northern end are compressional. Similarly, at least two other coronae exhibit compressional rings that are always the innermost of the circumferential tectonics, Ekajata [Squyres et al., 1992] and Sith [Stofan et al., 1992].

\section{Load Shape}

Previous viscous modeling of topographic relaxation on Venus [Stofon et al., 1991] indicated that an initially uncompensated plateau shape was required in order to form the characteristic topography of coronae. We have implicitly assumed that this is the case in the modeling shown so far. To test this assumption, we have run a model in which the initial topography has a cross section that would result from an outflow of a viscous fluid onto the surface. To determine the initial load shape, we adopt the similarity solution of Huppert [1982], who found the height of an axisymmetric outflow, as a function of radial position and time, to be given by

$$
h_{(r, t)}=\xi_{R}^{2 / 3}\left(3 Q \nu / g^{\prime}\right)^{1 / 4} t^{(\alpha-1) / 4} \psi\left(\xi / \xi_{R}\right)
$$

where $h$ is the height, $r$ is the radial distance from the flow center, $R$ is the radius of the flow, $t$ is time, $Q$ is the constant of proportionality between the volume of the flow and $t^{\alpha}, \nu$ is the viscosity, $g^{\prime}$ is the reduced gravity (equal to $g \Delta \rho / \rho$ ), and $\alpha$ is a nonnegative constant. At times longer than the emplacement time of the flow

$$
\begin{gathered}
\alpha=0 \\
\psi(z)=\left(\frac{3}{16}\right)^{1 / 3}\left(1-z^{2}\right)^{1 / 3} \\
\xi=\left(\frac{1}{3} g^{\prime} Q^{3} / \nu\right)^{-1 / 8} r t^{-1 / 8}
\end{gathered}
$$

while at the edge of the flow

$$
\xi_{R}=\left(\frac{2^{10}}{3^{4}} \pi^{3}\right)^{1 / 8}=0.894 \ldots
$$

At some time, $t$, after the flow has been emplaced, we take

$$
\begin{gathered}
C_{t}=\left(3 Q \nu / g^{\prime}\right)^{1 / 4} t^{-1 / 4} \\
C_{\xi}=\left(\frac{1}{3} g^{\prime} Q^{3} / \nu\right)^{-1 / 8} t^{-1 / 8}
\end{gathered}
$$

and

solving for these constants from the boundary conditions at the edge of the flow,

$$
\xi_{R}=C_{\xi}
$$

and at the center of the flow,

$$
h_{(r=0)}=\xi_{R}^{2 / 3} C_{t} \psi\left(\xi_{(r=0)} / \xi_{R}\right)
$$

Figure 10 shows the topography of this kind of load, initially $1 \mathrm{~km}$ in height, during relaxation. At no time during the process does the characteristic profile of a corona, with a central depression and an annular rim, form. Only the exterior moat develops as the lithosphere flexes under the imposed load. The inference drawn by Stofan et al. [1991] that the initial topography must be flat-topped and steep-sided therefore is robust to the addition of elastic rheology to relaxation modeling. Such plateau-shaped topography should result as the diapir that produced the initial radially fractured dome flattens against the underside of the lithosphere [Janes et al., 1992; Koch, 1994], and is also likely to be the source of concentric extensional fracturing concentrated at the edge of the plateau [Koch, 1994] which will later form the raised annulus.

\section{Discussion and Conclusions}

Finite element modeling of gravitationally driven viscoelastic relaxation on Venus indicates that the topog- 
raphy associated with coronae can develop over relatively short time spans and that actual relaxation rates will therefore be controlled by the cooling rate of the underlying diapir. This topography is then supported by a combination of buoyancy and flexural stresses and will persist through geologic time. Stresses on the outer wall of the flexural moat are in the proper orientation and, in some cases, of sufficient magnitude to produce the concentric extensional fracturing that has been observed. However, the stresses on the annular rim will not produce the fracturing that is generally observed there. A thicker crust and/or a higher near-surface temperature gradient will produce a narrower raised rim and moat, and a flatter interior bowl. Thinning of the crust and infilling with mantle material produce a lower interior bowl and deeper moat. while making the raised rim broader and higher relative to the depressed interior. All three conditions, thich crust, high temperature gradient, and localized crustal thinning due to mantle flow, produce higher differential stresses on the outer wall of the moat, increasing the probability of the formation of concentric extensional fracturing. The choice of specific non-Newtonian flow law does not significantly affect corona formation, since relaxation will still be rapid enough that it can instantaneously respond to the loss of buoyancy as the diapir cools. A necessary starting condition to the production of coronac is a flattopped plateau. The profiles that develop from our initial plateau shape show more sharply peaked rinıs than are observed. This difference is most likely duc to our initial plateau being very sharply defined. essentially as a step function, rather than having more rounded shoulders with shallower slopess

Acknowledgments. The authors gratefully acknowledge their indebtedness to $\mathrm{H}$. Jav Melosh for providing the TECTON code and instructions in its use. ()avid Jankowski for many helpful discussions. Brian Carcich for computational assistance, and Duane Bindschadler and an anonymous reviewer for their insightful and constructise comments. This work was supported by NASA grant NAcill. 1023.

\section{References}

Anderson, E.M., The Dynamics of Fauliung and Dyde Formation with Applications to Britarn, ind ed., 206 pp., Oliver and Boyd, Edinburgh. 1951.

Banerdt, W.B., and M.P. Golombek. Deformational models of rifting and folding on Venus, $J$. (irophys. Res., 93, 4759-4772, 1988.

Barsukov, V.L., et al., Preliminary evidence on the geology of Venus from radar measurements by the Venera 15 and 16 probes, Geokhimiya, 12, 1811-1820, 1984.

Barsukov, V.L., et al., The geology and geomorphology of the Venus surface as revealed by the radar images obtained by Veneras 15 and 16, Proc. Lunar Planet. Sci. Conf. 16th, Part 2, J. Geophys. Res., 91, suppl., D378D398, 1986.

Bindschadler, D.L., and E.M. Parmentier, Mantle flow tec- tonics and a ductile lower crust: Implications for the formation of large-scale features on Venus, J. Geophys. Res.. 95, 21,329-21,344, 1990.

Brace, W.F., and D.L. Kohlstedt, Limits on lithospheric stress imposed by laboratory experiments, $J$. Geophys. Res., 85, 6248-6252, 1980.

Byerlee, J., Friction of rocks, Pure Appl. Geophys, 116, 615-626, 1978.

Caristan, Y., The transition from high temperature creep to fracture in Maryland diabase, J. Geophys. Res., 87. 6781-6790, 1982.

Cathles, L.M., The Viscosity of the Earth's Mantle, 386 pp., Princeton University Press, Princeton, N. J., 1975.

Goetze, C., The mechanisms of creep in olivine, Philos. Trans. R. Soc. London A., 288, 99-119, 1978.

Grimm, R.E., and S.C. Solomon, Viscous relaxation of impact crater relief on Venus: Constraints on crustal thickness and thermal gradient, J. Geophys. Res., 93, 11,911$11,929,1988$

Herrick, R.R., and R.J. Phillips, Geological correlations with the interior density structure of Venus, $J$. Geophys. Res., 97, 16,017-16,034, 1992.

Huppert, H.E., The propagation of two-dimensional and axisymmetric viscous gravity currents over a rigid horizontal surface, J. Geophys. Res., 121, 43-58, 1982.

Janes, D.M., S.W. Squyres, D.L. Bindschadler, G. Baer, G. Schubert, V.L. Sharpton, and E.R. Stofan, Geophysical models for the formation and evolution of coronae on Venus, J. Geophys. Res., 97, 16,055-16,067, 1992.

Koch, D.M., A spreading drop model for plumes on Venus, J. Geophys. Res., 99, 2035-2052, 1994.

Mackwell, S.J., M.E. Zimmerman, D.L. Kohlstedt, and D.S. Scherber, Dry deformation of diabase: Implications for tectonics on Venus, Lunar Planet. Sci. Conf., XXV, 817818,1994

Melosh, H.J., and A. Raefsky, The dynamical origin of subduction zone topography, Geophys. J. R. Astron. Soc., $60,333-354,1980$.

Nikolayeva, O.V., L.B. Ronca, and A.T. Basilevsky, Circular structures on the plains of Venus as indicating geological history, Geokhimia, 5, 579-589, 1986.

Pronin, A.A. and E.R. Stofan, Coronae on Venus: Morphology, classification, and distribution, Icarus, 87, 452-474, 1990.

Sandwell, D.T., and G. Schubert, Evidence for retrograde lithospheric subduction on Venus, Science, 257, 766-770, $1992 \mathrm{a}$.

Sandwell, D.T., and G. Schubert, Flexural ridges, trenches, and outer rises a round coronae on Venus, J. Geophys. Res., 97, 16,069-16,083, 1992b.

Schultz, R.A., and M.T. Zuber, Observations, models, and mechanisms of failure of surface rocks surrounding planetary surface loads, J. Geophys. Res., 99, 14,691-14,702, 1994.

Solomon, S.C., and J.W. Head, Mechanics for lithospheric heat transport on Venus: Implications for tectonic style and volcanism, J. Geophys. Res., 87, 9236-9246, 1982.

Solomon, S.C., and J.W. Head, Lithospheric flexure beneath the Freyja Montes foredeep, Venus: Constraints on lithospheric thermal gradient and heat flow, Geophys. Res. Lett., 17, 1393-1396, 1990.

Solomon, S.C., and J.W. Head, Fundamental issues in the geology and geophysics of Venus, Science, 252, 252-260, 1991.

Solomon, S.C., J.W. Head, W.M. Kaula, D. McKenzie, B. Parsons, R.J. Phillips, G. Schubert, and M. Talwani, Venus tectonics: Initial analysis from Magellan, Science, 252, 297-312, 1991

Squyres, S.W., D.M. Janes, G. Baer, D.L. Bindschadler, G. 
Schubert, V.I. Sharpton, and E.R. Stofan, The morphology and evolution of coronae on Venus, J. Geophys. Res., $97,13,611-13,634,1992 \mathrm{a}$.

Squyres, S.W., D.G. Jankowski, M. Simons, S.C. Solomon, B.H. Hager, and G.E. McGill, Plains tectonism on Venus: The deformation belts of Lavinia Planitia, J. Geophys. Res., 97, 13,579-13,599, $1992 \mathrm{~b}$.

Stofan, E.R., and J.W. Head, Coronae of Mnemosyne Regio: Morphology and origin, Icarts, 83, 216-243, 1990.

Stofan, E.R., D.L. Bindschadler, J.W. Head, and E.M. Parmentier, Corona structures on Venus: Models of origin, J. Geophys. Res., 96, 20,933-20,946, 1991.

Stofan, E.R., V.L. Sharpton, G. Schubert, G. Baer, D.L. Bindschadler, D.M. Janes, and S.W. Squyres, Global distribution of coronae and related features on Venus: Implications for origin and relation to mantle processes, $J$. Geophys. Res., 97, 13,347-13,378, 1992.

Turcotte, D.L., and G. Schubert, Geodynamics: Applica- tions of Continuum Physics to Geological Problems, 450 pp., John Wiley, New York, 1982.

Zuber, M.T., Constraints on the lithospheric structure of Venus from mechanical models and tectonic surface features, Proc. Lunar Planet. Sci. Conf. 17th, Part 2, J. Geophys. Res., 92, suppl., E541-E551, 1987.

Zuber, M.T. and E.M. Parmentier, On the relationship between isostatic elevation and the wavelengths of tectonic surface features on Venus, Icarus, 85, 290-308, 1990.

D. M. Janes and S. W. Squyres, Center for Radiophysics and Space Research, Space Sciences Building, Cornell University, Ithaca, NY 14853-6801. (e-mail: janes@astrosun.tn.cornell.ed u)

(Received November 9, 1994; revised May 26, 1995; accepted June 2, 1995.) 
